\title{
Self-efficacy, relationship satisfaction, and social support: The quality of life of maternal caregivers of children with type 1 diabetes
}

\author{
Einar B Thorsteinsson ${ }^{\text {Corresp., }}{ }^{1}$, Natasha M Loi ${ }^{1}$, Kylie Rayner $^{1}$ \\ 1 Department of Psychology, University of New England, Armidale, Australia \\ Corresponding Author: Einar B Thorsteinsson \\ Email address: einarbt@gmail.com
}

Objectives. To examine maternal functioning and wellbeing as important aspects of a family's adaptation to chronic paediatric conditions, in particular, children with diabetes.

Method. This cross-sectional study investigated the difference between the perceived quality of life of mothers of children with diabetes $(n=63)$ and mothers of children without diabetes $(n=114)$. The study also examined the role of self-efficacy, relationship satisfaction, number of social support providers, and satisfaction with social support in predicting quality of life.

Results. Mothers who had a child with diabetes had lower quality of life measured by general health, vitality, social functioning, role-emotional, and mental health than mothers that did not have a child with diabetes. Self-efficacy, relationship satisfaction, and social support were significant predictors of quality of life (mental health domain).

Conclusion. In order to enhance their psychological wellbeing, mothers of children with diabetes require adequate psychosocial support. Other implications for research and potential interventions are discussed. 
Self-efficacy, relationship satisfaction, and social support: The quality of life of maternal caregivers of children with type 1 diabetes

\section{Author Note}

18 Psychology, University of New England, Australia. 
Abstract

24 Objectives. To examine maternal functioning and wellbeing as important aspects of a

25 family's adaptation to chronic paediatric conditions, in particular, children with diabetes.

26 Method. This cross-sectional study investigated the difference between the perceived

27 quality of life of mothers of children with diabetes $(n=63)$ and mothers of children without

28 diabetes $(n=114)$. The study also examined the role of self-efficacy, relationship

29 satisfaction, number of social support providers, and satisfaction with social support in

30 predicting quality of life.

31 Results. Mothers who had a child with diabetes had lower quality of life measured by

32 general health, vitality, social functioning, role-emotional, and mental health than mothers

33 that did not have a child with diabetes. Self-efficacy, relationship satisfaction, and social

34 support were significant predictors of quality of life (mental health domain).

35 Conclusion. In order to enhance their psychological wellbeing, mothers of children with

36 diabetes require adequate psychosocial support. Other implications for research and

37 potential interventions are discussed.

38

39

40 
41

Quality of life of maternal caregivers of children with type 1 diabetes and the role of selfefficacy, relationship satisfaction, and social support

Diabetes is a serious and rapidly escalating global health problem. In Australia, over 6000 children under 15 years of age had type 1 diabetes in 2013, representing 139 cases per 100,000 people (Australian Institute of Health and Welfare [AIHW], 2015). Type 1 diabetes is a disorder that mainly affects children and adolescents and is directly caused by immune system associated destruction of cells in the pancreas (Atkinson, Eisenbarth, \& Michels, 2014).

Diagnosis is based on blood glucose levels or an oral glucose-tolerance test (Atkinson et al., 2014). A diagnosis of type 1 diabetes has life-changing effects on families where a family member, most often the mother (e.g., Jaser, Whittemore, Ambrosino, Lindemann, \& Grey, 2009; Kovacs et al., 1990), will find herself in the role of caregiver. The caregiver role will increase daily mental pressures on the caregiver as they have to manage their child's behaviour and health-related factors to a larger extent than before the diagnosis. This can include overseeing the child's activity levels (e.g., increase exercise levels and reduce sedentary behaviour), imposing dietary restrictions (e.g., carbohydrate levels), ensuring glycaemic control, and monitoring for signs of hypoglycaemia and hyperglycaemia (e.g., Smart, Aslander-van Vliet, \& Waldron, 2009). Furthermore, the caregiver role varies depending on the age of the child and age of diagnosis varying the demands on the caregiver (Smaldone \& Ritholz, 2011; Whittemore, Jaser, Chao, Jang, \& Grey, 2012). With the diagnosis, and these new roles for the mother, comes worries (e.g., "will I manage to keep my child safe", "will the disease cause irreparable damage") that may affect mental and physical health (Lindström, Åman, Norberg, Forssberg, \& AnderzénCarlsson, 2017). Therefore, it is imperative that the caregiver has access to and receives satisfactory levels of social support (e.g., emotional, financial, belonging, and informational) 
64 from a strong social support network in order to attenuate the effects of caregiver stress on the

65 caregiver's mental health. The present study concentrates on type 1 diabetes and considers the 66 quality of life of maternal caregivers and the psychosocial resources that may play a part in

67 determining their perceived quality of life.

The difficulties in balancing the child's psychological needs in conjunction with the restrictions and treatment requirements imposed by diabetes can lead to frustration in the caregiver (e.g., Cunningham, Vesco, Dolan, \& Hood, 2011; Monaghan, Hilliard, Cogen, \&

Streisand, 2009). Diabetes can become burdensome, place a strain on financial resources, reduce the enjoyment of the parental role, and possibly impact upon both the physical and mental health of the caregiver (Helgeson, Becker, Escobar, \& Siminerio, 2012; Mellin, Neumark-Sztainer, \& Patterson, 2004).

Measuring the mothers' quality of life captures the broad impact of the child's illness on the mother's physical, psychological, and social wellbeing and functioning (Quittner et al., 1998). A poorer quality of life among caregivers has been reported among (a) parents of children with Down's syndrome (Hedov, Anneren, \& Wikblad, 2000), (b) families of children with autism spectrum disorder (Gardiner \& Iarocci, 2015), and (c) mothers of children with (i)

81 leukaemia (Yamazaki, Sokejima, Mizoue, Eboshida, \& Fukuhara, 2005), (ii) asthma (Cerdan, 82 Alpert, Moonie, Cyrkiel, \& Rue, 2012), and (iii) cerebral palsy (Eker \& Tuzun, 2004). mothers of children with type 1 diabetes has been shown to predict concurrent child psychological distress (Lopez, Mullins, Wolfe-Christensen, \& Bourdeau, 2008). Increased 
87 depressive symptoms in children (aged 10-18) with diabetes have been associated with diabetes-

88 related caregiver burden and diabetes-related family conflict (Hood et al., 2006).

89 In view of the differences in individuals' perceived quality of life, it is appropriate to

90 consider maternal resources that could be utilised to improve physical and mental health.

91 Elements of the transactional stress and coping (TSC) model of adjustment to chronic illness

92 (Hocking \& Lochman, 2005) provide a theoretical basis for this investigation. In the context of

93 the present study, the TSC model suggests that type 1 diabetes is a stressor the caregiver has to

94 adapt to (i.e., learn to cope and live with). The factors that affect the caregiver's ability to adapt

95 to their role are varied and can include the caregiver's social support levels, relationship with

96 their partner, general self-efficacy, coping strategies, stress appraisal, and socioeconomic status

97 (Azar \& Solomon, 2001). The present study focuses on aspects of the TSC model as supported

98 by the literature reviewed. Studies from parental wellbeing literature identify self-efficacy as one

99 of the personal resources associated with improved quality of life. General self-efficacy refers to

100 confidence in the ability to perform the necessary behaviours to influence or control the forces

101 affecting one's life in order to attain a certain outcome. Greater psychological wellbeing is

102 associated with higher levels of self-efficacy (Eiser, Riazi, Eiser, Hammersley, \& Tooke, 2001).

103 Self-efficacy is an important characteristic in alleviating the impact of psychological stress

104 (Chemers, Hu, \& Garcia, 2001) and in general parenting literature, parents' self-efficacy has

105 been reported to moderate the effects of stress on the parents' mental health (Kwok \& Wong,

106 2000). In research specific to diabetes, lower self-efficacy in parents was associated with

107 heightened levels of stress and anxiety (Streisand et al., 2008). As parents of children with

108 diabetes tend to be actively involved in the process of managing their child's illness, success in 
109 controlling the symptoms of the disease can result in heightened self-efficacy which may assist

110 in maintaining the parents' stable and emotional physical state (Lowes, Lyne, \& Gregory, 2004).

111 A second resource that may affect perceived quality of life is the quality of the parents'

112 marital/de-facto relationship. In a study involving the general population, individuals in

113 discordant relationships reported higher levels of general distress and poorer perceived health

114 (Whisman \& Uebelacker, 2006). Marital distress can also have a detrimental impact on children,

115 increasing the risk for poorer psychosocial adjustment (e.g., Repetti, Taylor, \& Seeman, 2002).

116 The presence of diabetes in a child has been associated with reduced family functioning (Crain,

117 Sussman, \& Weil Jr, 1966; Popp, Robinson, Britner, \& Blank, 2014). These findings are

118 compounded as significantly better diabetic control in children has been found when their

119 mothers report marital satisfaction (Marteau, Bloch, \& Baum, 1987).

120 Another resource that factors prominently in understanding parents' quality of life is the

121 parents' perceived social support levels. Studies indicate that social support has beneficial effects

122 on psychological wellbeing (Siedlecki, Salthouse, Oishi, \& Jeswani, 2014). Larger social support

123 networks and greater satisfaction with social support were significantly associated with better

124 psychological adjustment and reduced distress in mothers of children with chronic physical

125 conditions (Horton \& Wallander, 2001). Social support from the partners of mothers with

126 adolescents with type 1 diabetes plays an important role in reducing diabetes-related conflict

127 between mother and adolescent, and increases the adolescents' adherence to treatment

128 (Lewandowski \& Drotar, 2006). These findings have been supported with support for the

129 caregiver being related to better illness management (Carcone, Ellis, Weisz, \& Naar-King,

130 2011). Given the positive effects social support seems to have on conflict, illness management, 
131 and adherence, increased support may potentially contribute to a reduction in mental health strain

132 experienced by the caregivers.

133 The purpose of the present study was to examine maternal functioning and wellbeing

134 among mothers of children with diabetes by comparing them to mothers who do not have

135 children with diabetes. Given the significance of diabetes and the intrusiveness of the treatment

136 requirements, it is not surprising that mothers of children with diabetes are considered at risk for

137 psychosocial and family dysfunction as they are required to adapt to physical, emotional, social,

138 and financial challenges. Research suggests that the psychosocial functioning of mothers of

139 children with type 1 diabetes will differ to that of mothers of children without diabetes. As

140 research has suggested that fathers tend to be less involved in their child's diabetes management

141 (e.g., Seiffge-Krenke, 2002), our study focused solely on mothers. The following hypotheses

142 were tested: (a) maternal caregivers of children with diabetes would be more likely to report a

143 perceived poorer quality of life than mothers without a child with diabetes, and (b) lower levels

144 of general self-efficacy, less relationship satisfaction, less satisfaction with social support, and

145 fewer social support providers would be significant predictors of poorer maternal mental health

146 (the quality of life mental health domain) in mothers. The first hypothesis focuses on quality of

147 life while the second hypothesis focuses on the mental health domain of quality of life given the

148 strong focus on mental health in the literature. Increased burden associated with caregiving

149 affects the caregivers' quality of life which in turn affects their ability to continue in their role as

150 a caregiver and their ability to maintain good mental health. 


\section{Participants}

153 Mothers of a child with type 1 diabetes ("mothers of a child with type 1 diabetes group",

$154 n=63$ ) and mothers without a child with type 1 diabetes ("comparison group", $n=114$ ) were

155 recruited (Thorsteinsson, Rayner, \& Loi, 2016). The mothers were aged 25 to 52 ( $M=39.33$,

$156 S D=5.67)$. An invitation to participate in the study was provided to members of area chapters of

157 the Juvenile Diabetes Research Foundation throughout Australia, in an article placed in the

158 Diabetes Australia (NSW) quarterly magazine, "Issues", on an Australian online forum for

159 parents of a child or adolescent with type 1 diabetes, "Munted Pancreas", and through the clinics

160 of various physicians in Queensland who specialise in paediatric endocrinology. The comparison

161 group was recruited through school newsletters, parent online forums, and by word-of-mouth.

Mothers were excluded from participating if they were under 18 years of age or if their

163 child had also been diagnosed with another major illness or shown evidence of a developmental

164 disability.

165 The mean age of the mothers of children with diabetes and the mothers without children

166 with type 1 diabetes were similar (see Table 1). Most identified as Australian (91\%), were

167 currently in a relationship (84\%), had attained at least an undergraduate education degree (57\%),

168 and reported a relatively high income $(61 \%$ indicated a gross annual household income over

$169 \$ 62,000)$.

170 The mean age of the children with diabetes was 9.75 years $(S D=2.98$, ranging from 4 to

171 15). Time since diagnosis varied: from 1 to 3 month $(n=4,6.3 \%), 3$ and to 6 months $(n=2,3.2 \%)$,

1726 to 12 months $(n=9,14.3 \%)$, from 12 months to 2 years $(n=7,11.1 \%)$, and more than 2 years

$173(n=41,65.1 \%)$. Children's mental and physical health was good $(M=7.83, S D=1.58)$ based on the 
174 question "How would you rate mental and physical health of child" 1 (poor) to 10 (excellent).

175 Only one child had a rating of 3 while the remainder had ratings of 5 and above. When it came to

176 the mothers' biggest concerns, diabetes was highest for $68.3 \%(n=43)$, behavioural issues for

$1771.6 \%(n=1)$, social relationships $11.1 \%(n=7)$, and other for $19.0 \%(n=12)$.

\section{Materials}

179 The demographic questionnaire collected information pertaining to the mother including 180 age, ethnicity, highest level of education achieved, current employment status, marital status, 181 gross household income, residential location, number of children, and any family history of 182 diabetes. Information was also gathered on the demographic characteristics of each of the 183 mother's children including age, sex, whether or not each child had been diagnosed with 184 diabetes, and if a developmental disability or another chronic illness was present. The mother's quality of life was measured using the 36-item Short Form Health Survey

186 (SF-36; Ware, Snow, Kosinski, \& Gandek, 1993). Thirty-five of the items are aggregated into 187 eight subscale or domain scores: physical functioning, role-physical (i.e., role limitations due to 188 physical health), bodily pain, general health, vitality, social functioning, role-emotional, and 189 mental health. The remaining item was not needed for the present study; it asks respondents the 190 amount of change in their general health over the previous year. There is no total score for the

191 SF-36 and the response format varies greatly. Some items are answered on a 5-point Likert-type 192 scale from poor to excellent, some items are answered on a 3-point scale from yes, limited a lot 193 to no, not limited at all, and some on a 5-point scale from all of the time to none of the time. Each

194 of the domains is attributed a score between 0 and 100, with 100 representing optimal

195 functioning. Internal consistency of each domain ranged from .81 to .88 in the present study. 

self-efficacy with the aim of predicting how one copes with daily hassles and adapts to stressful life events. Each of the 10 items refers to successful coping and implies an internal-stable attribution of success (e.g., "I can usually handle whatever comes my way") with responses ranging from 1 (not at all true) to 4 (exactly true). Scores for each of the items are totalled and range from 10 to 40 with a higher score indicating a greater level of general self-efficacy. The present data yielded an alpha of .93 .

Relationship satisfaction was measured using the Dyadic Adjustment Scale (DAS;

Spanier, 1976), a widely utilised and well-validated 32-item measure of marital or partner

as well as four subscale scores assessing dyadic consensus, dyadic satisfaction, dyadic cohesion, and affectional expression. The total DAS score has been suggested as the best measure of dyadic quality (Sharpley \& Cross, 1982). The response format varies across items. Agreement and disagreement for various items (e.g., friends, religious matters, in-laws) are rated on a 6point Likert-type scale from always agree to always disagree. Some items are answered using a

211 yes-no or tick or do not tick dichotomy. Total scores can range from 0 to 140 with higher scores 212 suggesting better relationship satisfaction. The total scale had an internal consistency reliability 213 of .96 in the present study.

215 1987) is a brief measure of social support consisting of items in which a situation is presented

216 and asking for a list of supportive persons (up to 9 per question) and a rating of satisfaction with

217 support ranging from 1 (very dissatisfied) to 6 (very satisfied). For each individual, the summary

218 measures were the mean number of supporters and mean satisfaction (across all the questions). 
219 Higher mean scores in these scales imply a larger support group and greater satisfaction

220 respectively. Cronbach's alpha was .90 for support satisfaction and .94 for support numbers in

221 the present study.

\section{Procedure}

223 The self-administered questionnaire was available in both pencil-and-paper format and

224 online. Mothers were asked to read the Information Sheet which introduced the study and

225 highlighted the aims. The Information Sheet indicated that by completing and returning the

226 questionnaire, participants were confirming their consent to participate. For those participants

227 who completed the questionnaire online, it was compulsory for each participant to select 'yes'

228 when asked to indicate their consent before they were able to continue on to complete the online

229 questionnaire. A total of 14 questionnaires were returned in the post (nine from the mothers of a

230 child with type 1 diabetes group and five from the comparison group). Participation took

231 approximately 30 minutes and participants were advised they were able to discontinue at any

232 time without repercussion. Ethics approval was given by the University Of New England Human

233 Research Ethics Committee (HE07/034).

\section{Statistical Analyses}

235 Statistical analyses were completed using SPSS 21. Differences between groups were

236 assessed using: (a) statistical significance employing $t$-tests (Student, 1908) a standard test to

237 assess the differences between two independent means and (b) effect sizes employing Hedges' $g$

238 as it captures effect sizes in standard deviation units (Borenstein, Hedges, Higgins, \& Rothstein,

239 2009) and is regularly used when aggregating differences between groups using meta-analysis.

240 Hedges' $g$ also allows for the evaluation of differences between groups through its confidence

241 intervals. Multiple regression analysis (Tabachnick \& Fidell, 2001) was employed to evaluate 
242 different predictors of quality of life. The social support and general self-efficacy measures were

243 not completed by 14 and 17 participants, respectively. The relationship satisfaction questionnaire

244 was not completed by 16 participants who had earlier indicated they were currently in a

245 relationship. As entire measures were incomplete, means were not substituted for missing

246 variables but rather each case with the missing data was excluded from relevant analyses,

247 resulting in different sample sizes for different statistical analyses. A total of 18 participants

248 chose not to disclose household income data.

Results

250

251

252

253

254

255

256

257

258

259

260

261

262

263

264

\section{Preliminary Analyses}

Table 1 shows the differences between mothers of children with diabetes and without diabetes on the demographic variables. Mothers of a child with type 1 diabetes had significantly less formal education than those in the comparison group and they had significantly lower household income. The mothers of children without diabetes tended to reside in metropolitan areas of Australia more than the mothers of children with diabetes.

\section{Hypothesis 1: Perception of Quality of Life}

Mothers of a child with diabetes reported moderately lower mean quality of life scores than mothers without a child with diabetes for general health, vitality, social functioning, roleemotional, and mental health, see Table 2 .

\section{Hypothesis 2: Predictors of Quality of Life - Mental Health}

Better mental health was predicted ( $8 \%$ of the variance) by caring for a child without diabetes, living in a metropolitan location, having a partner, higher income, and lower education level, see Model 1 in Table 3 (beta $>|0.09|$ ). However, as Table 3 shows (Model 2; beta $>|0.09|$ ), the impact of these diminished and reversed (see relationship status) when other measures were 
265 added. Model 2 shows that better mental health is predicted by living in a metropolitan location,

266 lower education level, high social support (number and satisfaction), high relationship

267 satisfaction, and high general self-efficacy.

268

269

270

271

272

273

274

275

276

277

278

279

280

281

282

283

284

285

286

287

\section{Discussion}

The present findings enhance our understanding of the impact of having a child with diabetes and how maternal quality of life can potentially be improved. The results demonstrate the importance of considering the psychosocial status of the mother when treating a child with diabetes. Effective treatments for children and adolescents with diabetes should include the family, and in particular the mother, as an integral part of the treatment.

Mothers of children with diabetes reported a poorer quality of life than mothers of children without diabetes on five of eight quality of life domains: general health, vitality, social functioning, role-emotional, and mental health. These findings are consistent with findings indicating that parents of chronically ill children, and mothers in particular, are at risk for diminished psychological health (e.g., Hedov et al., 2000; Helgeson et al., 2012; Yamazaki et al., 2005). The current results imply that mothers of children with diabetes are more inclined to evaluate their health as poor and believe it is likely to worsen, more often experience fatigue, tend to have less opportunity for social interactions, have more frequent problems with daily activities as a result of emotional health, and tend to feel more nervous and depressed than mothers without a child with diabetes.

Both groups of mothers had similar scores on the three remaining quality of life domains. These domains have a strong physical component (i.e., physical functioning, role physical and bodily pain). As diabetes does not require extraordinary physical exertion on behalf of the caregiver, unlike some other chronic illnesses such as cerebral palsy (Eker \& Tuzun, 2004) or 
288 caring for a child with physical disabilities (Tong et al., 2002), it is not surprising that the two 289 groups of mothers had similar scores on these domains.

290 To understand why some mothers cope better than others, we examined different factors

291 that play a role in the caregiving experience. Examination of the mothers' reports of general self-

292 efficacy, relationship satisfaction, and social support was undertaken to understand further the

293 variables that may be relevant when assessing quality of life among maternal caregivers. As

294 hypothesised, this set of resources accounted for important differences in perceived mental

295 health quality of life. Mothers with a more positive view of their self-efficacy report better

296 functioning corresponding with other findings that have repeatedly shown self-efficacy to be

297 associated with better physical and psychological health (e.g., Motl, McAuley, Snook, \&

298 Gliottoni, 2009; Van der Horst, Paw, Twisk, \& Van Mechelen, 2007). The findings suggest that

299 mothers who do not feel adequately prepared to handle aspects of their child's diabetes may

300 allow this feeling of inadequacy to permeate other areas of her life. It is also possible that low

301 self-efficacy decreases the likelihood of the use of appropriate cognitive coping strategies to

302 effectively reduce negative effect. Thus mothers of a child with diabetes who report poor quality

303 of life could benefit from additional diabetes education and counselling or problem-solving

304 training to boost their confidence and increase self-efficacy. Doing so could help to improve the

305 mother's general wellbeing and ultimately result in better child-health outcomes.

306 The current findings suggest that having a child who places exceptional demands upon

307 the mother may result in less time and energy for contacts with informal support networks,

308 resulting in a reduction of the number of social support providers and ultimately having a

309 negative impact on maternal quality of life. This suggests that increasing the number of social

310 support providers will likely have a positive impact on quality of life and so increasing the 
311 opportunities for expansion of the social support network would be beneficial in improving the

312 mothers' quality of life, particularly in regional areas. Dissatisfaction with the quality of a close

313 dyadic relationship contributed to diminished mental health and wellbeing. Thus it is important

314 that the relationship between parents with children with diabetes be evaluated for poor

315 functioning.

316 Demographic factors were also found to negatively affect social and emotional

317 functioning, vitality, and mental health (i.e., living in a rural area with a child who has diabetes,

318 not being in a relationship, earning a low income, and having a higher level of education).

319 However, these demographic factors (i.e., location and household income) had smaller effects on

320 quality of life in Model 2. The limited effect for these factor in Model 2 can possibly be

321 attributed to the additional factors in Model 2 such as social support factors, relationship

322 satisfaction, and general self-efficacy. These additional factors seem to supersede the

323 demographics potentially capturing the underlying mechanism responsible for quality of life or

324 capturing an improved assessment of important variables that determine quality of life. Thus, not

325 having a partner negatively affected quality of life in Model 1 while in Model 2 this effect was

326 replaced with relationship satisfaction where the higher the satisfaction the better the quality of

327 life. Location and education did not change much from Model 1 to Model 2 suggesting that a

328 regional location combined with higher levels of education are more detrimental to quality of life

329 than a metropolitan location combined with lower levels of education. This may be caused by the

330 lack of access to services in regional locations putting more burden on caregivers. Furthermore,

331 caregivers with higher levels of education seem to feel the pressures of caregiving more (e.g.,

332 Ory, Hoffman, Yee, Tennstedt, \& Schulz, 1999). 
333 Limitations and Future Studies

334 The data in the present study is cross-sectional thus it cannot demonstrate causal

335 relationships or clarify causal direction. Longitudinal studies that monitor change over time in

336 maternal adjustment with diabetes management, along with repeated monitoring of the child's

337 medical and psychosocial outcomes, could clarify the findings presented here further. Such

338 monitoring might help reveal causal relationships where mothers' status, with or without a

339 children with diabetes, may affect social support, self-efficacy, and relationship satisfaction that,

340 in turn, affects quality of life (see Table 3 Model 2). Furthermore, additional comparison groups

341 could be included such as mothers of children with asthma or other chronic diseases and

342 questions such as time of diagnosis.

343 Future research could strengthen the present findings by including medical data

344 pertaining to the child's metabolic control. While it is a limitation of the present study that the

345 severity of the children's diabetes was not assessed, research is inconsistent on the role of disease

346 severity. Some research has shown that illness severity may not play a role in the distress of the

347 caregiver (e.g., Canning, Harris, \& Kelleher, 1996; Rodrigues \& Patterson, 2007). However, it is

348 possible that illness severity may moderate the pattern of relationships found here, particularly if

349 severity affects the mother's appraisal of the controllability of her child's diabetes, which in turn

350 affects her perception of self-efficacy. Future studies should also consider the effects of sleep

351 disruption in parents of children with type 1 diabetes (Landau et al., 2014) given the impact sleep

352 quality can have on health (Buysse, Grunstein, Horne, \& Lavie, 2010).

353 There were significant socioeconomic differences between the two comparison groups

354 (i.e., household weekly income and level of education) which may have resulted in some bias

355 especially in the mental health and social functioning domains of quality of life. 


\section{Conclusion}

The present study demonstrates the importance of social support providers, relationship

358 satisfaction, and general self-efficacy to the psychological adjustment of mothers of children

359 with diabetes. Treatment of diabetes in children and adolescents should include close monitoring

360 of the mother's mental health and the provision of appropriate psychosocial support. 
363

364

365

366

367

368

369

370

371

372

373

374

375

376

377

378

379

380

381

382

383

384

385

386

387

388

389

390

391

392

393

394

395

396

397

398

399

400

401

402

403

404

405

Atkinson, M. A., Eisenbarth, G. S., \& Michels, A. W. (2014). Type 1 diabetes. The Lancet, 383, 69-82. doi:10.1016/S0140-6736(13)60591-7

Australian Institute of Health and Welfare [AIHW]. (2015). Prevalence of type 1 diabetes among children aged 0-14 in Australia 2013. Retrieved from: http://www.aihw.gov.au/WorkArea/DownloadAsset.aspx?id=60129553222

Azar, R., \& Solomon, C. R. (2001). Coping strategies of parents facing child diabetes mellitus. Journal of Pediatric Nursing, 16, 418-428. doi:10.1053/jpdn.2001.27878

Borenstein, M., Hedges, L. V., Higgins, J. P. T., \& Rothstein, H. R. (2009). Introduction to metaanalysis. West Sussex: Wiley.

Buysse, D. J., Grunstein, R., Horne, J., \& Lavie, P. (2010). Can an improvement in sleep positively impact on health? Sleep Medicine Reviews, 14, 405-410. doi:10.1016/j.smrv.2010.02.001

Canning, R. D., Harris, E. S., \& Kelleher, K. J. (1996). Factors predicting distress among caregivers to children with chronic medical conditions. Journal of Pediatric Psychology, 21, 735-749. doi:10.1093/jpepsy/21.5.735

Carcone, A. I., Ellis, D. A., Weisz, A., \& Naar-King, S. (2011). Social support for diabetes illness management: Supporting adolescents and caregivers. Journal of Developmental and Behavioral Pediatrics, 32, 581. doi:10.1097/DBP.0b013e31822c1a27

Cerdan, N. S., Alpert, P. T., Moonie, S., Cyrkiel, D., \& Rue, S. (2012). Asthma severity in children and the quality of life of their parents. Applied Nursing Research, 25, 131-137. doi:10.1016/j.apnr.2011.01.002

Chemers, H. H., Hu, L., \& Garcia, B. F. (2001). Academic self-efficacy and first-year college performance and adjustment. Journal of Educational Psychology, 93, 55-64. doi:10.1037/0022-0663.93.1.55

Crain, A. J., Sussman, M. B., \& Weil Jr, W. B. (1966). Effects of a diabetic child on marital integration and related measures of family functioning. Journal of Health and Human Behavior, 7, 122-127. doi:10.2307/2948728

Cunningham, N. R., Vesco, A. T., Dolan, L. M., \& Hood, K. K. (2011). From caregiver psychological distress to adolescent glycemic control: The mediating role of perceived burden around diabetes management. Journal of Pediatric Psychology, 36, 196-205. doi:10.1093/jpepsy/jsq071

Dyches, T. T., Christensen, R., Harper, J. M., Mandleco, B., \& Roper, S. O. (2016). Respite care for single mothers of children with autism spectrum disorders. Journal of Autism and Developmental Disorders, 46, 812-824. doi:10.1007/s10803-015-2618-z

Dykens, E. M., Fisher, M. H., Taylor, J. L., Lambert, W., \& Miodrag, N. (2014). Reducing distress in mothers of children with autism and other disabilities: A randomized trial. Pediatrics, 134, e454-e463. doi:10.1542/peds.2013-3164

Eiser, J. R., Riazi, A., Eiser, C., Hammersley, S., \& Tooke, J. E. (2001). Predictors of psychological well-being in types 1 and 2 diabetes. Psychology and Health, 16, 99-110. doi: $10.1080 / 08870440108405492$

Eker, L., \& Tuzun, E. H. (2004). An evaluation of quality of life of mothers of children with cerebral palsy. Disability and Rehabilitation, 26, 1354-1359. doi:10.1080/09638280400000187 
406

407

408

409

410

411

412

413

414

415

416

417

418

419

420

421

422

423

424

425

426

427

428

429

430

431

432

433

434

435

436

437

438

439

440

441

442

443

444

445

446

447

448

449

450

451

Gardiner, E., \& Iarocci, G. (2015). Family quality of life and ASD: The role of child adaptive functioning and behavior problems. Autism Research, 8, 199-213. doi:10.1002/aur.1442

Hedov, G., Anneren, G., \& Wikblad, K. (2000). Self-perceived health in Swedish parents of children with Down's syndrome. Quality of Life Research, 9, 415-422. doi:10.1023/A:1008910527481

Helgeson, V. S., Becker, D., Escobar, O., \& Siminerio, L. (2012). Families with children with diabetes: Implications of parent stress for parent and child health. Journal of Pediatric Psychology, 37, 467-478. doi:10.1093/jpepsy/jsr110

Hocking, M. C., \& Lochman, J. E. (2005). Applying the transactional stress and coping model to sickle cell disorder and insulin-dependent diabetes mellitus: Identifying psychosocial variables related to adjustment and intervention. Clinical Child and Family Psychology Review, 8, 221-246. doi:10.1007/s10567-005-6667-2

Hood, K. K., Huestis, S., Maher, A., Butler, D., Volkening, L., \& Laffel, L. (2006). Depressive symptoms in children and adolescents with type 1 diabetes: Associated with diabetesspecific characteristics. Diabetes Care, 29, 1389-1391. doi:10.2337/dc06-0087

Horton, T. V., \& Wallander, J. L. (2001). Hope and social support as resilience factors against psychological distress of mothers who care for children with chronic physical conditions. Rehabilitation Psychology, 46, 382-399. doi:10.1037/0090-5550.46.4.382

Jaser, S. S., Whittemore, R., Ambrosino, J. M., Lindemann, E., \& Grey, M. (2009). Coping and psychosocial adjustment in mothers of young children with type 1 diabetes. Children's Health Care, 38, 91-106. doi:10.1080/02739610902813229

Kovacs, M., Iyengar, S., Goldston, D., Obrosky, D. S., Stewart, J., \& Marsh, J. (1990). Psychological functioning among mothers of children with insulin-dependent diabetes mellitus: A longitudinal study. Journal of Consulting and Clinical Psychology, 58, 189. doi:10.1037/0022-006X.58.2.189

Kuhlthau, K. (2012). Parent caregivers of children with disabilities. In R. C. Talley \& J. E. Crews (Eds.), Multiple dimensions of caregiving and disability (pp. 67-82). New York, NY: Springer.

Kwok, S., \& Wong, D. (2000). Mental health of parents with young children in Hong Kong: The roles of parenting stress and parenting self-efficacy. Child and Family Social Work, 5, 57-65. doi:10.1046/j.1365-2206.2000.00138.x

Landau, Z., Rachmiel, M., Pinhas-Hamiel, O., Boaz, M., Bar-Dayan, Y., Wainstein, J., \& Tauman, R. (2014). Parental sleep quality and continuous glucose monitoring system use in children with type 1 diabetes. Acta Diabetologica, 51, 499-503. doi:10.1007/s00592013-0545-Z

Lewandowski, A., \& Drotar, D. (2006). The relationship between parent-reported social support and adherence to medical treatment in families of adolescents with type 1 diabetes. Journal of Pediatric Psychology, 32, 427-436. doi:10.1093/jpepsy/js1037

Lindström, C., Åman, J., Norberg, A. L., Forssberg, M., \& Anderzén-Carlsson, A. (2017). "Mission impossible": The mothering of a child with type 1 diabetes - From the perspective of mothers experiencing burnout. Journal of Pediatric Nursing, 36, 149-156. doi:10.1016/j.pedn.2017.06.002

Lopez, W. L., Mullins, L. L., Wolfe-Christensen, C., \& Bourdeau, T. (2008). The relation between parental psychological distress and adolescent anxiety in youths with chronic illnesses: The mediating effect of perceived child vulnerability. Children's Health Care, 37, 171-182. doi:10.1080/02739610802151464 
452

453

454

455

456

457

458

459

460

461

462

463

464

465

466

467

468

469

470

471

472

473

474

475

476

477

478

479

480

481

482

483

484

485

486

487

488

489

490

491

492

493

494

495
Lowes, L., Lyne, P., \& Gregory, J. W. (2004). Childhood diabetes: Parents' experience of home management and the first year following diagnosis. Diabetic Medicine, 21, 531-538. doi:10.1111/j.1464-5491.2004.01193.x

Marteau, T. M., Bloch, S., \& Baum, J. D. (1987). Family life and diabetic control. Journal of Child Psychology and Psychiatry, 28, 823-833. doi:10.1111/j.1469-7610.1987.tb00671.x

Mellin, A. E., Neumark-Sztainer, D., \& Patterson, J. M. (2004). Parenting adolescent girls with type 1 diabetes: Parents' perspective. Journal of Pediatric Psychology, 29, 221- 230. doi:10.1093/jpepsy/jsh023

Monaghan, M. C., Hilliard, M. E., Cogen, F. R., \& Streisand, R. (2009). Nighttime caregiving behaviors among parents of young children with type 1 diabetes: Associations with illness characteristics and parent functioning. Families, Systems, \& Health, 27, 28-38. doi:10.1037/a0014770

Motl, R. W., McAuley, E., Snook, E. M., \& Gliottoni, R. C. (2009). Physical activity and quality of life in multiple sclerosis: Intermediary roles of disability, fatigue, mood, pain, selfefficacy and social support. Psychology, Health and Medicine, 14, 111-124. doi:10.1080/13548500802241902

Muscara, F., Burke, K., McCarthy, M. C., Anderson, V. A., Hearps, S. J., Hearps, S. J., . . . Nicholson, J. M. (2015). Parent distress reactions following a serious illness or injury in their child: A protocol paper for the take a breath cohort study. BMC Psychiatry, 15, 111. doi:10.1186/s12888-015-0519-5

Nabors, L., \& Bartz, J. (2013). Type I diabetes in children: Facilitating adherence to medical regimens. In Type 1 diabetes (pp. 433-444). Online: INTECH. doi:10.5772/45927

Ory, M. G., Hoffman, R. R.,III., Yee, J. L., Tennstedt, S., \& Schulz, R. (1999). Prevalence and impact of caregiving: A detailed comparison between dementia and nondementia caregivers. The Gerontologist, 39, 177-185. doi:10.093/geront/39.2.177

Popp, J. M., Robinson, J. L., Britner, P. A., \& Blank, T. O. (2014). Parent adaptation and family functioning in relation to narratives of children with chronic illness. Journal of Pediatric Nursing, 29, 58-64. doi:10.1016/j.pedn.2013.07.004

Quittner, A. L., Espelage, D. L., Opipari, L. C., Carter, B., Eid, N., \& Eigen, H. (1998). Role strain in couples with and without a child with a chronic illness: Associations with marital satisfaction, intimacy, and daily mood. Health Psychology, 17, 112-124. doi:10.1037/0278-6133.17.2.112

Repetti, R. L., Taylor, S. E., \& Seeman, T. E. (2002). Risky families: Family social environments and the mental and physical health of offspring. Psychological Bulletin, 128, 330-366. doi:10.1037//0033-2909.128.2.330

Rodrigues, N., \& Patterson, J. M. (2007). Impact of severity of a child's chronic condition on the functioning of two-parent families. Journal of Pediatric Psychology, 32, 417-426. doi:10.1093/jpepsy/js1031

Sarason, I. G., Sarason, B. R., Shearin, E. N., \& Pierce, G. R. (1987). A brief measure of social support: Practical and theoretical implications. Journal of Social and Personal Relationships, 4, 497-510. doi:10.1177/0265407587044007

Schwarzer, R., \& Jerusalem, M. (1995). Generalized Self-Efficacy Scale. In J. Weinman, S. Wright \& M. Johnston (Eds.), Measures in health psychology: A user's portfolio. Causal and control beliefs (pp. 35-37). Windsor, UK: NFER-NELSON. 
496

497

498

499

500

501

502

503

504

505

506

507

508

509

510

511

512

513

514

515

516

517

518

519

520

521

522

523

524

525

526

527

528

529

530

531

532

533

534

535

536

537

538

539

540

541
Seiffge-Krenke, I. (2002). "Come on, say something, Dad!” Communication and coping in fathers of diabetic adolescents. Journal of Pediatric Psychology, 27, 439-450. doi:10.1093/jpepsy/27.5.439

Sharpley, C. F., \& Cross, D. G. (1982). A psychometric evaluation of the Spanier Dyadic Adjustment Scale. Journal of Marriage and the Family, 44, 739-741. doi:10.2307/351594

Siedlecki, K. L., Salthouse, T. A., Oishi, S., \& Jeswani, S. (2014). The relationship between social support and subjective well-being across age. Social indicators research, 117, 561576. doi:10.1007/s11205-013-0361-4

Smaldone, A., \& Ritholz, M. D. (2011). Perceptions of parenting children with type 1 diabetes diagnosed in early childhood. Journal of Pediatric Health Care, 25, 87-95. doi:10.1016/j.pedhc.2009.09.003

Smart, C., Aslander-van Vliet, E., \& Waldron, S. (2009). Nutritional management in children and adolescents with diabetes. Pediatric Diabetes, 10, 100-117. doi:10.1111/pedi.12175

Spanier, G. B. (1976). Measuring dyadic adjustment: New scales for assessing the quality of marriage and similar dyads. Journal of Marriage and the Family, 38, 15-28. doi: $10.2307 / 350547$

Streisand, R., Mackey, E. R., Elliot, B. M., Mednick, L., Slaughter, I. M., Turek, J., \& Austin, A. (2008). Parental anxiety and depression associated with caring for a child newly diagnosed with type 1 diabetes: Opportunities for education and counseling. Patient Education and Counseling, 73, 333-338. doi:10.1016/j.pec.2008.06.014

Student. (1908). The probable error of a mean. Biometrika, 6, 1-25. doi:10.2307/2331554

Tabachnick, B. G., \& Fidell, L., S. (2001). Using multivariate statistics. Sydney: Allyn and Bacon.

Thorsteinsson, E. B., Rayner, K., \& Loi, N. M. (2016). Children with diabetes: Mothers' quality of life. [Data file]. figshare. Retrieved from http://dx.doi.org/10.6084/m9.figshare.3208549

Tong, H. C., Kandala, G., Haig, A. J., Nelson, V. S., Yamakawa, K. S. J., \& Shin, K. Y. (2002). Physical functioning in female caregivers of children with physical disabilities compared with female caregivers of children with a chronic medical condition. Archives of Pediatrics and Adolescent Medicine, 156, 1138-1142. doi:10.1001/archpedi.156.11.1138

Van der Horst, K., Paw, M. J. C. A., Twisk, J. W. R., \& Van Mechelen, W. (2007). A brief review on correlates of physical activity and sedentariness in youth. Medicine and Science in Sports and Exercise, 39, 1241-1250. doi:10.1249/mss.0b013e318059bf35

Wagner, J. L., Chaney, J. M., Hommel, K. A., Page, M. C., Mullins, L. L., White, M. M., \& Jarvis, J. N. (2003). The influence of parental distress on child depressive symptoms in juvenile rheumatic diseases: The moderating effect of illness intrusiveness. Journal of Pediatric Psychology, 28, 453-462. doi:10.1093/jpepsy/jsg036

Ware, J. E., Snow, K. K., Kosinski, M., \& Gandek, B. (1993). SF-36 Health Survey Manual. Boston, MA: The Health Institute, New England Medical Center.

Whisman, M. A., \& Uebelacker, L. A. (2006). Impairment and distress associated with relationship discord in a national sample of married or cohabiting adults. Journal of Family Psychology, 20, 369-377. doi:10.1037/0893-3200.20.3.369

Whittemore, R., Jaser, S., Chao, A., Jang, M., \& Grey, M. (2012). Psychological experience of parents of children with type 1 diabetes: A systematic mixed-studies review. The Diabetes Educator, 38, 562-579. doi:10.1177/01457212445216 
542 Witt, W. P., Gottlieb, C. A., Hampton, J., \& Litzelman, K. (2009). The impact of childhood 543

544 545 activity limitations on parental health, mental health, and workdays lost in the United States. Academic Pediatrics, 9, 263-269. doi:10.1016/j.acap.2009.02.008

Yamazaki, S., Sokejima, S., Mizoue, T., Eboshida, A., \& Fukuhara, S. (2005). Health-related quality of life of mothers of children with leukaemia in Japan. Quality of Life Research, 14, 1079-1085. doi:10.1007/s11136-004-3288-z 


\section{Table $\mathbf{1}$ (on next page)}

Comparisons of sociodemographic variables for mothers with and without a child with diabetes 
1 Table 1

2 Comparisons of Sociodemographic Variables for Mothers With and Without a Child with Diabetes

\begin{tabular}{|c|c|c|c|}
\hline Sociodemographic variable & $\begin{array}{l}\text { Mothers of child } \\
\text { with diabetes } \\
(n=63)\end{array}$ & $\begin{array}{l}\text { Mothers of child } \\
\text { without diabetes } \\
\quad(n=114)\end{array}$ & Comparison \\
\hline Mother's age in years, $M(S D)$ & $39.76(5.20)$ & $39.10(5.92)$ & $t(175)=-0.75, p=.456$ \\
\hline Number of children, $M(S D)$ & $2.49(0.93)$ & $2.44(1.02)$ & $t(175)=-0.34, p=.731$ \\
\hline Level of education, $M(S D)$ & $4.22(0.98)$ & $4.73(1.02)$ & $t(175)=3.22, p=.002$ \\
\hline Household weekly income, $M(S D, n)$ & $3.53(1.44,53)$ & $4.06(1.19,106)$ & $t(157)=2.47, p=.015$ \\
\hline Ethnicity, $n(\%)$ & & & $\chi^{2}(1)=3.54, p=.089, \Phi=-.14$ \\
\hline - Australian & $61(96.8)$ & $101(88.6)$ & \\
\hline - European/Asian/Other & $2(3.2)$ & $13(11.4)$ & \\
\hline Marital status, $n(\%)$ & & & $\chi^{2}(1)=1.07, p=.344, \Phi=.08$ \\
\hline - In a relationship & $53(84.1)$ & $102(89.5)$ & \\
\hline - Not in a relationship & $10(15.9)$ & $12(10.5)$ & \\
\hline Employment status, $n(\%)$ & & & $\chi^{2}(4)=7.36, p=.118$, Cramer's $\mathrm{V}=.20$ \\
\hline - Employed part-time & $18(28.6)$ & $48(42.1)$ & \\
\hline - Student (part or full time) & $4(6.3)$ & $8(7.0)$ & \\
\hline - Homemaker & $22(34.9)$ & $20(17.5)$ & \\
\hline - Employed casually & $4(6.3)$ & $9(7.9)$ & \\
\hline - Employed full-time & $15(23.8)$ & $29(25.4)$ & \\
\hline Location, $n(\%)$ & & & $\chi^{2}(1)=4.65, p=.047, \Phi=.16$ \\
\hline - Metropolitan area & $41(65.1)$ & $91(79.8)$ & \\
\hline - Regional area & $22(34.9)$ & $23(20.2)$ & \\
\hline Family history of diabetes, $n(\%)$ & & & $\chi^{2}(1)=1.61, p=.261, \Phi=.10$ \\
\hline - Yes & $22(34.9)$ & $51(44.7)$ & \\
\hline - No & $41(65.1)$ & $63(55.3)$ & \\
\hline
\end{tabular}

3 Note. Education level: High school $=3$, Vocational qualification $=4$, Undergraduate $=5$, Postgraduate $=6$;

4 Household weekly income: up to $\$ 400=1, \$ 401-\$ 800=2, \$ 801-\$ 1200=3, \$ 1201-\$ 1600=4,>\$ 1600=5$. Twotailed $p$ values reported. 
Table 2 (on next page)

Comparison of mothers with diabetic children and without diabetic children 
1 Table 2

2 Comparison of Mothers of Children with Type 1 Diabetes and Mothers of Children without Diabetes

\begin{tabular}{|c|c|c|c|c|c|c|c|}
\hline \multirow[b]{2}{*}{ Measure } & \multicolumn{2}{|c|}{$\begin{array}{c}\text { Mothers of child } \\
\text { with type } 1 \\
\text { diabetes }(n= \\
63)\end{array}$} & \multicolumn{2}{|c|}{$\begin{array}{c}\text { Mothers of } \\
\text { child without } \\
\text { diabetes . }(n= \\
114)\end{array}$} & \multirow[b]{2}{*}{$t(175)$} & \multirow[b]{2}{*}{$p$} & \multirow[b]{2}{*}{ Hedges'g } \\
\hline & $M$ & $S D$ & $M$ & $S D$ & & & \\
\hline General health & 63.83 & 21.73 & 73.82 & 18.09 & 3.27 & .001 & $0.51[0.20,0.82]$ \\
\hline Vitality & 44.29 & 23.02 & 54.43 & 20.49 & 3.02 & .003 & $0.47[0.16,0.78]$ \\
\hline Social functioning & 70.04 & 25.94 & 80.70 & 21.63 & 2.92 & .004 & $0.46[0.15,0.77]$ \\
\hline Role-emotional & 56.08 & 45.13 & 74.85 & 38.80 & 2.91 & .004 & $0.45[0.14,0.77]$ \\
\hline Mental health & 61.40 & 20.66 & 71.44 & 16.87 & 3.50 & .001 & $0.55[0.23,0.86]$ \\
\hline Physical functioning & 90.08 & 15.41 & 91.05 & 12.61 & 0.45 & .651 & $0.07[-0.24,0.38]$ \\
\hline Role physical & 78.17 & 32.84 & 79.17 & 35.19 & 0.18 & .854 & $0.03[-0.28,0.34]$ \\
\hline Bodily pain & 72.33 & 18.13 & 72.39 & 18.78 & 0.02 & .986 & $0.00[-0.30,0.31]$ \\
\hline
\end{tabular}

3 


\section{Table 3 (on next page)}

Summary of hierarchical regression analysis of scores on the quality of life mental health domain 
Table 3

2 Summary of Hierarchical Regression Analysis of Scores on the Quality of Life Mental Health Domain

\begin{tabular}{|c|c|c|c|c|c|c|}
\hline \multirow[b]{2}{*}{ Predictor } & \multirow[b]{2}{*}{$B$} & \multicolumn{2}{|c|}{$95 \% \mathrm{CI}$ for $B$} & \multirow[b]{2}{*}{$\beta$} & \multirow[b]{2}{*}{$r$} & \multirow[b]{2}{*}{$s r^{2}$} \\
\hline & & Lower & Upper & & & \\
\hline \multicolumn{7}{|l|}{ Model 1} \\
\hline Mother group & -5.80 & -12.49 & 0.89 & -0.15 & -.18 & .02 \\
\hline Location & -4.38 & -12.25 & 3.49 & -0.10 & -.19 & .01 \\
\hline Relationship status & -20.10 & -44.69 & 4.50 & -0.14 & -.18 & .02 \\
\hline Household income & 2.84 & -0.12 & 5.80 & 0.19 & .23 & .03 \\
\hline Education & -2.06 & -5.24 & 1.12 & -0.12 & -.01 & .01 \\
\hline \multicolumn{7}{|l|}{ Model 2} \\
\hline Mother group & 0.81 & -5.13 & 6.75 & 0.02 & -.18 & $<.01$ \\
\hline Location & -6.21 & -13.08 & 0.66 & -0.15 & -.19 & .03 \\
\hline Relationship status & 8.41 & -14.07 & 30.90 & 0.06 & -.18 & $<.01$ \\
\hline Household income & 0.91 & -1.63 & 3.45 & 0.06 & .23 & $<.01$ \\
\hline Education & -2.46 & -5.20 & 0.29 & -0.14 & -.01 & .03 \\
\hline Number of social supports & $1.55^{*}$ & 0.09 & 3.02 & 0.19 & .41 & .04 \\
\hline Social support satisfaction & $3.61 *$ & -0.30 & 7.53 & 0.18 & .41 & .03 \\
\hline Relationship satisfaction & 0.14 & 0.00 & 0.29 & 0.18 & .36 & .04 \\
\hline General self-efficacy & $1.46^{*}$ & 0.77 & 2.15 & 0.36 & .45 & .13 \\
\hline
\end{tabular}

\footnotetext{
Note. $s r^{2}=$ squared semi-partial correlation (squared Part correlation from SPSS); $r=$ zero-order

correlation. The Quality of Life Mental Health Domain is attributed a score between 0 and 100, with 100 representing optimal functioning. Mother group: $1=$ mother without a child with type 1 diabetes group, 2 = mothers of a child with type 1 diabetes group; Location: 1 = metropolitan, 2 = regional; Relationship status: $1=$ partner, $2=$ no partner; and Household income (gross weekly): $1=$ up to $\$ 400,2=\$ 401$ to $\$ 800,3=\$ 801$ to $\$ 1,200,4=\$ 1,201$ to $\$ 1,600,5=\$ 1,601$ or more. Education: 3 = High School (year 10 or year 12), $4=$ Vocational Training Course/Diploma, $5=$ Undergraduate, and $6=$ Postgraduate.

Model 1: Adjusted $R^{2}=.08, F(5,117)=3.09, p=.012$

Model 2: Adjusted $R^{2}=.36, F(9,113)=8.53, p<.001$

Change $R^{2}=.29, F(4,113)=13.65, p<.001$.

$* p<.05$
} 